\title{
THE SOUTH AFRICAN MILITARY IN TRANSITION: PART 1 - FROM STRATEGY FORMULATION TO STRATEGY FORMATION
}

\author{
Gerhard M. Louw \\ South African National Defence Force \\ Abel Esterhuyse \\ Stellenbosch University
}

"Good strategy presumes good anthropology and sociology. Some of the greatest military blunders of all time have resulted from juvenile evaluations in this department."

\begin{abstract}
By 2013, sufficient evidence had become publicly available to confirm what defence analysts had been suspecting for a while now: the military effectiveness of the South African National Defence Force (SANDF) is deficient. This article proposes that this condition is due to strategic failure, brought about by the dynamic interaction between the preferred strategic management model of the organisation and its acquired strategic culture(s). The study on which this article reports, further suggests that a design school strategic management model best explains the method towards the SANDF's current condition of organisational entropy, but that its root cause actually lies in a dichotomous strategic culture. In combination, these two variables conspired to diminish the defence force's responsiveness to its operational context, resulting in the formation of inappropriate strategy that prevented the SANDF from achieving military effectiveness. While the authors consider the article to be hypothesis generating, it also has an exploratory dimension and paves the way for a validational study at a later stage. Part 1 therefore argues towards a strategic management model that could explain the SANDF's strategy formulation process, its method of ensuring that strategic outcomes correlate with strategic intent, and ultimately its weakness in accounting for the external environment in realised

Scientia Militaria, South African Journal of Military Studies, Vol 42, Nr 2, 2014, pp. 1-26. doi : $10.5787 / 42-2-1092$ strategy. This first part mainly employs inductive reasoning and draws its conclusions from an eclectic literary review that included business studies and dynamic systems theory.
\end{abstract}




\section{Introduction}

If one is to believe the Minister of Defence and Military Veterans, the SANDF appears to be on the verge of its second major transformation since its establishment in 1994. On 23 May 2013, the minister again delivered her preamble to the annual debate on the defence budget vote. This time, though, the tone of the minister's communication differed markedly from that of the previous year. ${ }^{2}$ Whereas the 2012 version fixated on domestic departmental matters such as the adjustment of salaries, the establishment of crèches at military bases, and the institution of a military ombudsman for managing grievance procedures, ${ }^{3}$ the latest speech displayed a marked concern with the military effectiveness of the armed forces. This interest seems to have arisen subsequent to the Battle in Bangui, fought two months previously in the Central African Republic (CAR) by elements of the SANDF. Some of the speculative doubts regarding the performance of the SANDF in operations were confirmed in this encounter, ${ }^{4}$ and "... in the aftermath of these events, the department has had to conduct deep introspection and review, the result of which will have serious implications for the work and organisation of our armed forces, particularly during this financial year". 5

As ministerial epiphanies go, this one in particular had been a long time in revealing: almost two decades, in fact, since the promulgation of the White Paper on National Defence $1996^{6}$ and the Defence Review $1998 .^{7}$ Serving as the foundation of the SANDF's intended military strategy, these venerable defence policy publications initiated defence reform (or 'transformation', as South Africans are wont to call it) after the country's peaceful revolution in 1994. Moreover, these very same policy publications were still in force - in spite of government professing a concern with military effectiveness, and committing itself to a revision of defence policy at the same time ${ }^{8}$ - fifteen years later, when the SANDF evacuated its casualties from Bangui in 2013. Mounting evidence from a variety of sources (including those from official accounts, such as the draft Defence Review 2012) ${ }^{9}$ lately seems to suggest that "[t]he SANDF has both feet on a slippery slope to nowhere: it cannot fund operations, training or maintenance properly and it is in no position to push ahead with even the most critical equipment projects." 10 Defence policy and intended military strategy have produced neither the results the South African government apparently desires, nor what the armed forces seemingly need. Instead, the SANDF seems to have undergone a steady and inevitable deterioration of its military capabilities, and have become disappointingly ineffective as a result. Essentially, the SANDF's realised strategy appears to have resulted in the maximisation of entropy: a term that physical scientists usually employ in connection with closed thermodynamic systems, but which researchers in the social 
sciences could use in connection with some organisations as well. ${ }^{11}$ Through the achievement of these strategic outcomes, the SANDF seems to be validating Henry Mintzberg's claim that not all intended strategies are realised, and not all realised strategies were intended. ${ }^{12}$

A defence force in a condition of virtual paralysis, unable to respond effectively to the demands placed upon it, should be cause of trepidation for politicians and citizens alike. Still, the study on which this article is based, was less concerned with the SANDF's military ineffectiveness as a de facto strategic outcome (which the parliamentary opposition has been reporting since $2009,{ }^{13}$ and the printed media had picked up as well), ${ }^{14}$ than with the causes of what appears to be a strategic miscarriage. Given the surfeit of evidence that supports the proposition of military stasis, the article therefore assumes that the transformation strategy of the armed forces since the publication of the Defence Review of 1998 has resulted in decreased military effectiveness, and that the current organisational entropy is not only unacceptably high, but also still increasing. A confirmatory or descriptive study of the SANDF's condition would consequently serve little purpose at this time, but uncertainties remain regarding the causes of strategic failure. Whereas the Deputy Minister of Defence had asked, during the 1998 Defence Budget speech, whether the SANDF was simply an old wolf in sheep's clothing, the current study was therefore intent upon answering a more recent question: what could, by the year 2013, have caused the SANDF to masquerade as an old sheep in lion's clothing? ${ }^{15}$ Answers to this question should not only result in a better understanding of the origins of the phenomenon, but may also inform new, appropriate strategies to rehabilitate the armed forces. Taking all of the above into account, a full-blown explanatory study would probably offer the best solution to the problem; however, the difficulty is that such a study, using theory and empirical evidence to validate a plausible hypothesis, would be far too ambitious for a single article (even if rendered in two parts).

Previous research suggests that one of the primary causes of the SANDF's military ineffectiveness may reside in an inappropriate strategy, brought about by the dynamic interaction between the organisation's strategic management model and its strategic culture. ${ }^{16}$ Since all strategic behaviour is also cultural behaviour, the study chose to approach the subject of military strategy from an ideological/cultural perspective. ${ }^{17}$ Furthermore, it deliberately considered generic concepts of strategy from both the military and business domains, and touched (however superficially) on systems theory as well. While this method may provoke conservative theorists, it was nevertheless indispensable for the attainment of the theoretical validity of the article. Flowing from these suppositions, one may now proceed to deal with the overarching research problem in two stages: in the first, employing basic theory to 
develop a hypothesis and, in the second, validating the proposed interpretative structure and developing a theory. The study therefore only attended to the research question posed in the first stage: which strategic management model could a researcher gainfully use to explain the causes of the SANDF's current condition of organisational entropy? The study thus had one foot in the realm of scientific theory, and another in the domain of social practice. It argued towards acceptance of an elementary strategic management model that could plausibly explain the manner of the SANDF's strategy formulation, its method of aligning strategic outcomes with its intended strategy during implementation, and its lack of responsiveness to emergent effects from its operational environment.

\section{Defining the parameters of a management model}

In spite of what those of reductionist/logical empiricist convictions may believe, the strategic management model proposed in this article does not purport to be an objective representation of the actual system. Its validity does not depend on it being true or false when compared with the empirical evidence, but rather on its usefulness and appropriateness to resolve the research problem. ${ }^{18}$ The proposed model would have to account for the fact that, although an intended strategy may not always have been explicitly formulated (or even necessary) for coherent activities to transpire, it would almost invariably have been present before the SANDF took action at strategic level. ${ }^{19}$ One may also approach the defence force's strategy from the other end, though: as a posteriori, realised strategy, and then work back towards identifiable patterns in the stream of leadership decisions that had resulted in strategy formation over time. In contrast to the SANDF's intended strategy, its realised strategy would only have become visible subsequent to its implementation, being a product of evolutionary adaptations that the intended strategy underwent during its execution. ${ }^{20}$ For the researcher, a study of an intended strategy (such as could be deduced from the Defence Reviews of 1998 or 2014, for example) would reveal much of the strategists' normative orientations and perceptual mind-sets at the time of strategy formulation. An interrogation of realised strategy, on the other hand, would expose the organisation's actual strategic behaviour, as it had responded to influences from its changing operational environment during strategy formation. To ensure the article's theoretical validity, therefore, the proposed strategic management model would have to account for both approaches. ${ }^{21}$

Although rather shy on the mechanics of strategy formulation, Henry Mintzberg provides a way of combining the possible outcomes of strategy formation in a single diagram. First, he describes those intended strategies that largely become realised, calling them 'deliberate strategies'. Executing a deliberate strategy means that an organisation would - while being responsive to emerging environmental 
influences - actively manage its intended strategy, in conscious pursuance of achieving its desired ends. Second, Mintzberg notes that some intended strategies remain essentially unrealised, due to unrealistic expectations of the strategy, misjudgements of environmental influences, or unresponsiveness to changes in any of these settings.

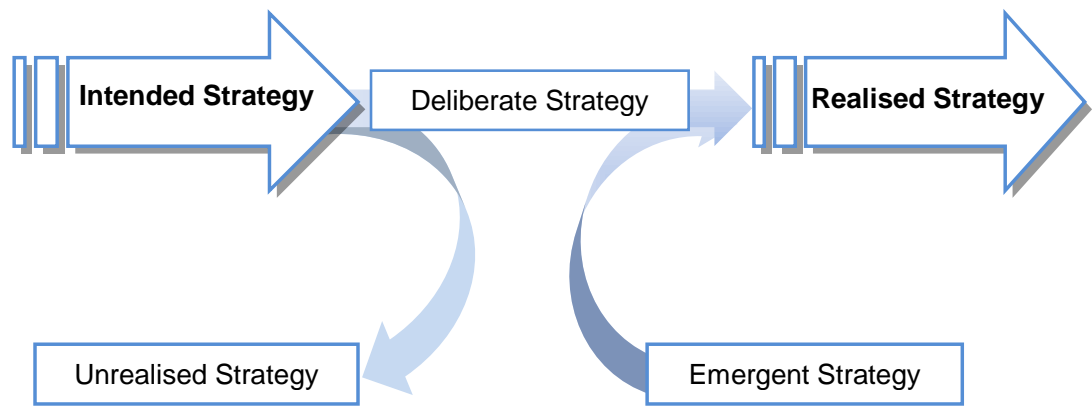

\section{Figure 1: Types of strategy ${ }^{22}$}

Third, Mintzberg mentions the realisation of strategy that is for the most part unintended, either because strategists conceived the intended strategy poorly, or subordinates did not understand it clearly, or leadership - through inaction - allowed an emergent strategy to supersede it. ${ }^{23}$ While all realised strategies will contain elements of emergent strategy (those influences from the external environment that cannot be controlled or eliminated, but which can be mitigated or exploited), unresponsive organisations are particularly susceptible to the undesirable effects of emergence. "Strategy abhors a vacuum: if the strategic function is lacking, strategic effect will be generated by the casual accumulation of tactical and operational outcomes." 24 Organisations can therefore not choose whether they should strategize and display strategic behaviour or not - doing nothing also becomes strategy formation, albeit by default rather than by intent.

In compiling a strategic management model, the current study also had to consider the notion that the organisational structure of any system is a major determinant of the establishment's ability to contend with environmental complexity. An investigation into the causes of the SANDF's strategic entropy should therefore include an interrogation of the defence force's structure as well. ${ }^{25}$ However, the current study was more interested in the development of a model that would explain the organisation's strategic behaviour, than in describing the attributes of the structure of the organisation. This approach becomes all the more viable if one bears in mind that “... strategies developed without considering the 
possible behavioural aspect of organisational reality are doomed to fail" ${ }^{26}$ The study therefore simply assumed that the SANDF, like most military institutions, is an example of a classical hierarchy or 'machine bureaucracy', a structure characterised by a centralisation of authority, emphasising the differentiation between a small number of thinkers at the top and a large number of implementers in the lower echelons. Machine bureaucracies are best suited for the execution of highly articulated strategic plans, within relatively stable environments, according to standardised procedures, and using detached forms of control. In other words, machine bureaucracies connote best with stabiles that manage given strategies, rather than with mobiles that effect strategic transformation. ${ }^{27}$ While it is true that machine bureaucracies, too, are sometimes in need of a major reformulation of their strategies (as with the SANDF after 1994), there is sufficient evidence that their chief executives view themselves as custodians of existing strategies rather than as the champions of innovative new ones. ${ }^{28}$

Another matter in need of confirmation is that all militaries are concurrently engaged in the forming of at least two types of military strategy: an operational strategy (based upon existing military capabilities), and a force developmental strategy (based upon future threats, tasks and/or objectives). ${ }^{29}$ Given that the SANDF has not been required to form strategies for major combat operations since its establishment, the study will henceforth confine itself to (peacetime) force development strategy only. This immediately creates another potential challenge in that the perception among many analysts is that military effectiveness - that attribute with which the SANDF apparently has a problem - is only empirically measurable after the armed forces' deployment in active operations. Fortunately, others are of the opinion that the operations research approach to military competency is inadvisable, for at least two reasons:

- First, operations research primarily focuses on the war mode and the tactical level of war - the outcomes of battles, or the expression of fighting power; and

- Second, the operations research method is primarily interested in quantitative research, using empirical data and measuring effectiveness in terms of material assets or historical outcomes.

The article therefore prefers Brooks and Stanley's framework ${ }^{30}$ for military effectiveness, which conveniently allows for a study of realised military strategy in peacetime (focused primarily on the political and strategic levels) and the adoption of a qualitative research methodology.

Finally, the article is an affirmation of the fact that the body of knowledge on strategic management has expanded vastly since the days when strategy was 
associated exclusively with the military. Any investigation into the evolution of the SANDF's strategy formation since its founding would consequently be obliged to venture beyond traditional strategic studies and account for these management theories as well. The article will therefore introduce the static and dynamic models of strategic management right from the start, albeit only through a brief discussion of limited notional depth. As the argument unfolds, the article will concurrently report on a critical analysis of the generic military strategy formulation method, thereby suggesting the first potential cause of defence's current lack of military effectiveness, being the adoption of a management model that was ill suited to resolve the SANDF's strategic problem during the first decade of its existence (1994-2004).

\section{The military's penchant for 'rational' strategy formulation}

While strategists have never had an easy time in the past, the complexity of their function seems to be increasing more rapidly of late. Regulating the interaction between the organisation and its operational environment has become the prime function of strategic management, one that strategists have traditionally resolved by reducing the conundrum into discrete, functional segments, and then analysing each in turn. However, in the face of perceptions that such functional approaches invariably result in departmental rivalries, sub-optimal performance at organisational interfaces, increasing entropy, and eventual stagnation and decline, strategists are lately obliged to adopt a holistic, multi-disciplinary and systemic view of strategic management. ${ }^{31}$ They have come to understand that strategic visioning and strategic analysis are equally important in strategy formation; moreover, that strategists' assumptions and beliefs, as well as the socio-political dynamics of the institution, are decisive in the form and content of the strategy that an organisation produces. ${ }^{32}$ This does not mean that modern dynamic systems thinking have replaced the traditional view of organisations as pyramids, though. In the main, organisations still view themselves as hierarchies that operate in accordance with strategies generated at the top, subsequently to be cascaded down to the lowest ranks during the implementation of strategy. It seems that the absence of an agreement on a lucid, unambiguous and reliable model of the strategic management process is fuelling the continuing debate among strategic management schools. ${ }^{33}$ In the interests of simplification, the current study assumed that two broad philosophies are contesting the issue: the design (prescriptive, static) school of thought, and the dynamic (crafting, emergent) school. ${ }^{34}$ Whereas the discussion that follows initially deals with these two schools as theoretical constructs at opposite ends of a strategic management scale, in practice, the difference between strategic managers' approaches would be largely a matter of degree only. 
At the one end, strategists of the design school live in a pedantic universe, where they look back from an envisioned, desired future state and formulate allembracing strategies for implementation in the present. To them, strategic management is a linear, sequential process in which an organisation formulates, implements and then controls a strategy that it deems appropriate to achieve an imagined, preferred condition in the future - drawing a straight line between intended strategy and realised strategy, in other words. ${ }^{35}$ Militaries are apparently fond of using the design-school strategic management model, believing that -

- $\quad$ Strategy is proactive and anticipatory;

- Strategy is directive, hierarchical, comprehensive and holistic; and

- Any strategy carries the risk of either failing to achieve one's objectives, and/or of providing significant advantage to one's adversaries. ${ }^{36}$

Military strategists traditionally determine the measure of this risk by gauging the imbalance between the ends (objectives), means (resources), and ways (methods) of strategy; thus, the planner only has to bring these three elements into a better balance to enhance the probabilities of strategic success. ${ }^{37}$ Finally, the military strategist also believes that “... strategy is a disciplined thought process that seeks to apply a degree of rationality and linearity to an environment that may or may not be either, so that effective planning can be accomplished". ${ }^{38}$ In spite of their preference for a rational and scientific approach to strategy making, military strategists are however also mindful that the validity of their environmental analysis is dependent upon their perception and understanding of world events, especially in relation to their own religious and political beliefs. Since it is at this point that the study began to establish a connection between defence's strategic management model and its strategic culture, the following is worth quoting in full:

Consequently, the strategist's Weltanschauung is both an objective view of the existing current environment and an anticipatory appreciation of the implications of continuities and change for the nation's future well-being. Appreciating that the strategic environment possesses the characteristics of a system of systems and exhibits some of the attributes of chaos theory, the strategist accepts that the future is not predictable but believes it can be influenced and shaped towards more favorable outcomes. His weltanschauung makes the strategist sensitive to what national interests are and the threats, challenges, and opportunities in regard to them. However, a new, focused strategic appraisal is conducted when circumstances demand a new strategy or a review of the existing strategy is undertaken. Understanding the stimulus or the requirement for the 
strategy is the first step in the strategic appraisal. It not only provides the strategist's focus and motivation, but will ultimately lend legitimacy, authority and impetus to the appraisal and strategy formulation process and the subsequent [sic] implementation of the strategy. $^{39}$

From the above, the reader can make at least two important deductions: first, the strategist's personal worldview is indeed a crucial factor in strategy formulation, in spite of the alleged objectivity of the 'scientific method' employed by the military. That which the military therefore thinks of as 'rational' may not be so logical after all. Design school theory also supports this deduction in the sense that it considers organisational values (the beliefs and preferences of top managers) and social responsibilities (the ethics of the society in which the organisation is embedded) to be important in strategy formulation. ${ }^{40} \mathrm{~A}$ second deduction is that the construction and management of military strategy seem to be a formal, sequential and hierarchical process. The military strategist not only thinks of conscious deliberation as being superior to action in general, but also as preceding strategic implementation in time; consequently, management tends to separate the work of strategic thinkers from that of the doers. ${ }^{41}$ In the linear universe of defence planners, therefore, the worldview of the military strategist greatly influences strategy formulation, but becomes largely irrelevant during the implementation of that strategy. The current article elaborates further on this theme in the following section, which deals with the military's traditional method of strategy evaluation and selection.

\section{Testing military strategy for appropriateness}

For the armed forces, a viable strategy option should firstly contain an explication of the objectives or 'ends' of the strategy, serving defence policy interests. Secondly, it should entail a description of the resources or 'means' (tangible and intangible) that the strategy proposes to employ; and finally, it would include the 'ways', describing the methods to be employed during the execution of the strategy. After applying an evaluation process to each of the strategy options, defence leadership eventually selects and refines an intended strategy, ready to undergo detailed planning and scheduling. ${ }^{42}$ For an intended strategy to reach the stage of execution, it would therefore have had to pass three tests: those of suitability, feasibility and acceptability. ${ }^{43}$ At first glance, the application of these strategic assessment criteria appears deceptively simple and straightforward - until one understands that both the goals of strategy and the context of their formulation are political rather than functional. Take the norm of suitability, for example. It attaches to the strategic ends, and is a measurement of whether the particular 
strategic option will have the desired effect, solve the strategic problem, and achieve its policy objectives. A judgement of 'unsuitable' should immediately invalidate the particular strategic alternative, thus saving the strategist the trouble of applying any of the other tests. ${ }^{44}$ Next, the feasibility test is an assessment of whether the available resources are adequate to execute the proposed course of action, or will be so in future. The feasibility test is largely a quantitative assessment of material resources and military capabilities (often thought of as 'restraints' rather than as 'constraints'), but subjective judgement regarding the armed forces' morale, skill, fighting spirit, intellectual capacity and popular support also come into play. Even though the tests for suitability and feasibility are complex and require mature professional judgement, they still appear to be largely rational and reduce well into the linear model previously described. ${ }^{45}$ The same does not apply to the last test the assessment of acceptability - which is usually applied to the 'ways' of the strategy, in an effort to determine the practicability of the proposed strategic method.

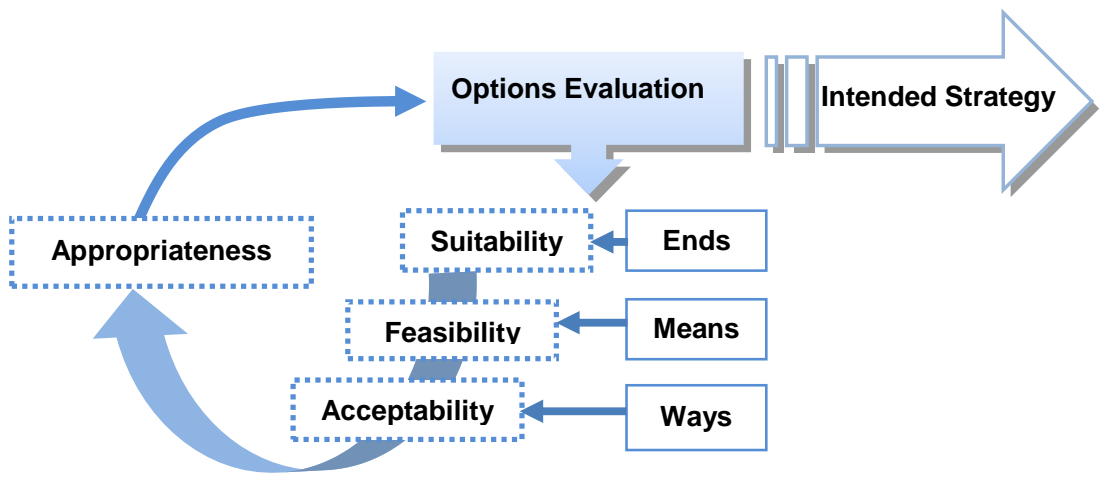

Figure 2: Evaluating strategy options

The question of acceptability goes much deeper and wider than the mere contemplation of techniques and processes, though. It is certainly rational, in the sense that it requires the strategist to be proficient in military practice, but it is also biased. It is not only an expression of the strategist's personal worldview, but accounts for the value preferences of political decision-makers and society as well. ${ }^{46}$ For a defence policy or military strategy to pass the acceptability test emphatically, it would therefore have to conform to the values and norms of the whole of the Clausewitzian trinity, namely those of government, those of the people, and those of the military. ${ }^{47}$ Testing the strategy option for acceptability thus assumes a comprehensive judgement of the proposed strategy in its entirety, constrained as it is by decision-makers' philosophical and ideological convictions, i.e. their ethics, 
sense of morality and knowledge of legality. Since the strategist conducts this test through the cognitive filter of a particular worldview, it is simultaneously much more holistic and subjective than the tests for suitability and feasibility are. This test will not only express a verdict on the 'ways' of a strategy option, but they will also influence the decision-maker's judgement of the suitability of 'ends' and the feasibility of 'means'. 48

Consequently, individuals who are steeped in a specific strategic culture may consider a particular strategy option as being suitable and/or feasible, while those with different philosophical convictions may find the same strategy to be 'unacceptable' in the ends that it seeks, or the means that it intends employing. What is more, the issue of acceptability is bound to exert a more subtle, pervasive influence over strategy as time passes. For example, a strategy that is both suitable and feasible may be successful in the short term, but if that same strategy is in conflict with the values and norms of its parent society, it will ultimately fail. ${ }^{49}$ Strategy evaluation in the design mode is therefore a proactive process, conducted by individuals or teams who are not only cognisant of their physical environment (external and organisational), but at the same time also subconsciously constrained by the preferences of their particular worldview. While the reasons for a potential failure of the strategy to qualify may be apparent to those involved, it is in the passing of the tests that the evaluation of the subjectivity, contestability and ultimate inconclusiveness of the strategy becomes apparent. Such an evaluation will therefore not assist in predicting whether a particular strategy is fit for purpose or whether it will be successful; it would merely serve as judgement of the acceptability of the proposed strategy in the eyes of those that conducted the assessment. ${ }^{50}$ A strategy encumbered with abstract, ambiguous ends could, for example, still lose its focus during implementation, and an intended strategy with inadequate means could also become a strategy by default - in effect, a mere function of material factors, which achieves only those objectives that management arbitrarily decides to fund. ${ }^{51}$ None of the above bodes well for militaries that are blind to the presence of biased worldviews in strategists' supposedly rational strategy formulation processes. Nevertheless, a defence force that anticipates the inevitability of change, which recognises the fundamental elements of change when it occurs, and which responds appropriately to changes in the external environment may yet avoid the pitfalls of subjective thinking. Adopting these conceptual remedies, however, requires an infusion of dynamic systems thinking into the design school method that the article has reported on thus far. 


\section{Feedback loops as enablers of responsiveness}

The existence of closed information loops, feeding back into the decisionmaking bodies of an organisation, is a fundamental attribute of all complex systems. In their most basic form, feedback loops are akin to John Boyd's now-famous OODA loop, which refers to a decision cycle of observe, orient, decide and act. (Boyd's model suggests that strategists base their decisions on observations of the working environment, oriented through the filters of the particular planner's culture, cognitive ability and previous experience. Since each strategist of an organisation will have his or her personal set of beliefs, the complexity of decision-making will increase exponentially as the number of culturally diverse participants in the strategy formulation process grows. $)^{52}$ Feedback loops also establish dependencies between management process inputs and outputs, creating the potential for non-linear, multifaceted modes of organisational behaviour. ${ }^{53}$

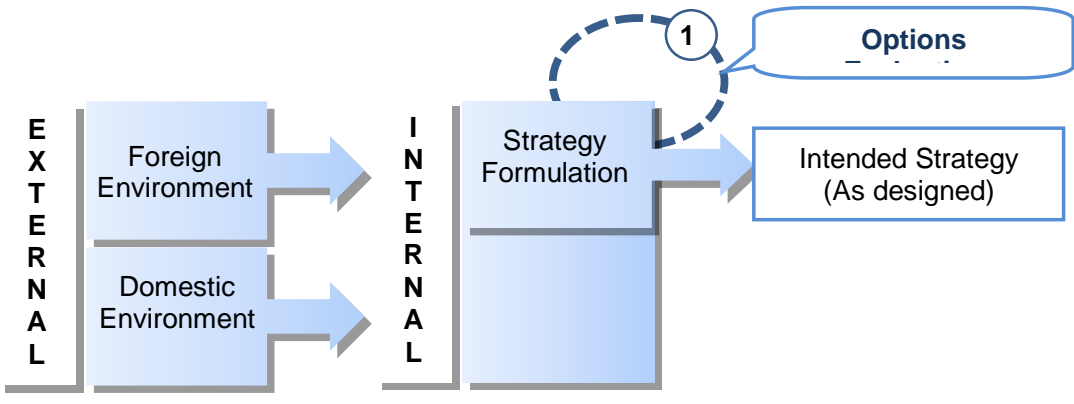

Figure 3: Formulating intended strategy

By feeding information regarding the process outputs - for example, refined strategy options or the outcomes of deliberate strategy - back to decision-makers, these loops enable the organisation to respond appropriately to changes in its operating environment. While it is common for stochastic feedback loops to occur naturally, institutions often create these mechanisms intentionally to capitalise on the promise that they hold. Properly utilised, feedback loops reduce the differential between that which the organisation desires (intended strategy) and the outcomes that it actually achieves (realised strategy). As was discussed earlier in this article, the evaluation of strategy options thus becomes an example of a closed feedback loop within the strategy formulation process (Figure 3). While such a feedback loop will not assist an organisation in becoming more responsive to its environment directly, it could nevertheless encourage an institution to learn about itself, to clarify its organisational values and norms, and to shape a coherent strategic culture. For 
the SANDF, the introduction of such a consensus-forming mechanism would have been very helpful prior to the drafting of the Defence Reviews of 1998 and 2014.

Introducing a closed loop into the linear strategy formulation process again suggests that the philosophies of the two strategic management schools under discussion are not mutually exclusive, but merely reside at opposite ends of a continuum. Every social system (such as the SANDF) seems to employ information feedback loops to facilitate the discourse with its environment. It is only in their consideration of the scope, frequency and import of these loops that the two philosophies differ. One could consequently augment the linear framework further by introducing more elements of dynamic systems theory into the process. For example, an effective organisation will usually employ another internal, closed-loop feedback mechanism to ensure convergence between the intent of the strategy and its actual outcomes. In this case, the feedback loop would be comprised of performance monitoring, comparing the results of strategy implementation with the strategy's intended objectives, and resulting in an adjustment to a deliberate strategy that should narrow the gap between the two. As illustrated below (Figure 4), this loop is part of the strategy formation process. It facilitates responsiveness to changes in the internal environment and encourages organisational learning. ${ }^{54}$

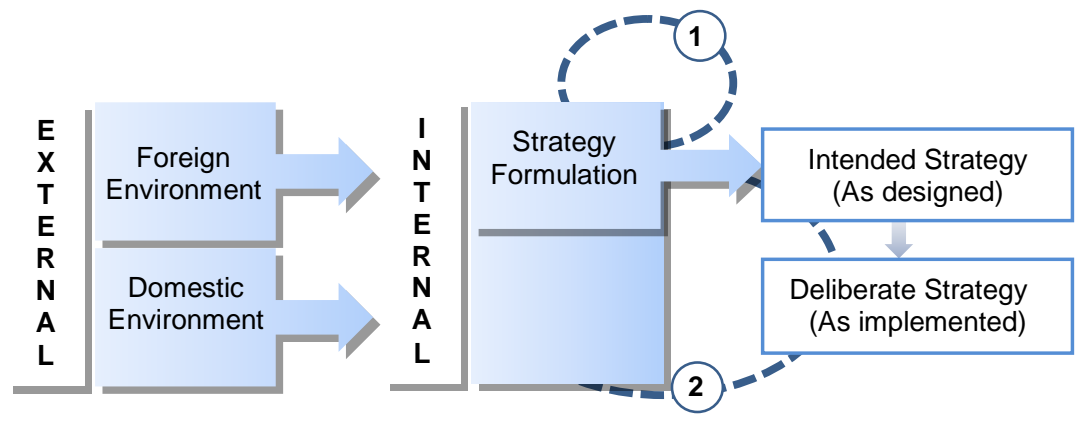

Figure 4: Forming deliberate strategy

The insertion of a second feedback loop into the diagram now moderates the initial conclusion, which was that the worldview of the military strategist in the design school model would have a definitive influence on strategy formulation, but only a minor effect on the subsequent implementation of the strategy. It now appears that the more extended the implementation of strategy (as would be the case with the SANDF's force development strategy, for example), the greater the opportunity for the strategist's culture to, through utilisation of the second feedback loop, influence strategic outcomes. Described in terms of Stafford Beer's Viable System Model 
(VSM) - an example of the 'hard' systems approach - the second loop would be part of the integration mechanism of the organisation: a monitoring/control device, premised upon the enhancement of institutional efficiency and synergy. The second loop links strategic intent with implementation of the strategy, organisational objectives with individual interests, and institutional policy with institutional product. ${ }^{55}$ With the basic elements of a potential strategic management model for the military thus described, the discussion now turns towards the first hints of an explanation for the SANDF's lack of strategic responsiveness.

\section{Intimations of risk to the SANDF}

Henry Mintzberg is of the opinion that the schematic, as developed thus far, contains two possible sources of strategic risk. The first is that the design school's need for an articulate strategy promotes inflexibility, which is anathema to both organisational learning and responsiveness alike. ${ }^{56}$ There are sound reasons for declaring an explicit strategy, though. Like policy, one can interrogate and debate an explicit strategy. It can also aid organisational coherence, serve as a rallying point for the generation of internal support, and reassure external stakeholders that the organisation is attending to their needs - all of which the second feedback loop facilitates. However, the flipside of the same argument is that an overt strategy, designed to focus strategic activities, may also limit the organisation's peripheral vision, its learning ability and ultimately its responsiveness to changes in its operating environment. The more clearly the organisation articulates its strategy, and the longer it maintains the paradigm of intended strategy, the more difficult it may become to change it when there is clearly a need to do so. ${ }^{57}$ (This argument would be more applicable to organisations steeped in the design school than to those of a dynamic bent. To the latter, a clear strategy simply implies a more straightforward process of finding and changing those elements of the strategy that, as time marches on, appear to be out of step with environmental realities.) The second risk is that an enunciated strategy (again, like policy) may, if not actively managed, provoke a false sense of understanding among the stakeholders that have an interest in its execution. As was suggested in the section on strategy evaluation, a host of political and functional considerations accompany the selection and implementation of a strategy. Since it is not possible to explain all of these supporting concepts in a single strategy declaration, that which decision-makers take the strategy for may actually be a caricature of what it truly is. The risk of misunderstandings increases further when outsiders, with little knowledge of the organisation's core business, are involved. ${ }^{58}$ Under such conditions, one may readily find the incomprehension and strategic naiveté of the inept abetting the dogmatism and intransigence of the supposedly knowledgeable. 
The two feedback loops previously described occur entirely within an organisation, and are therefore characteristic of a closed system (such as a military in peacetime). Introducing a third feedback loop at this time not only opens up the organisational system, but also points to the design school model's most debilitating flaw. This loop recognises the organisation's impact on its surroundings and accounts for emergent influences from its functional environment at the same time. The mechanism enables the responsive strategist to modify the intended strategy of the organisation by adjusting those target settings that the second feedback loop initially sought to achieve. ${ }^{59}$ Since the strategist in this mode has to adapt continually to changing sets of assumptions, it is hard to plan for this process. However, if effectively utilised this feedback loop should bring about reasoned, purposeful adjustments to the original intended strategy. This activity goes to the heart of an organisation's responsiveness and addresses the very essence of the debate between the two strategic management schools.

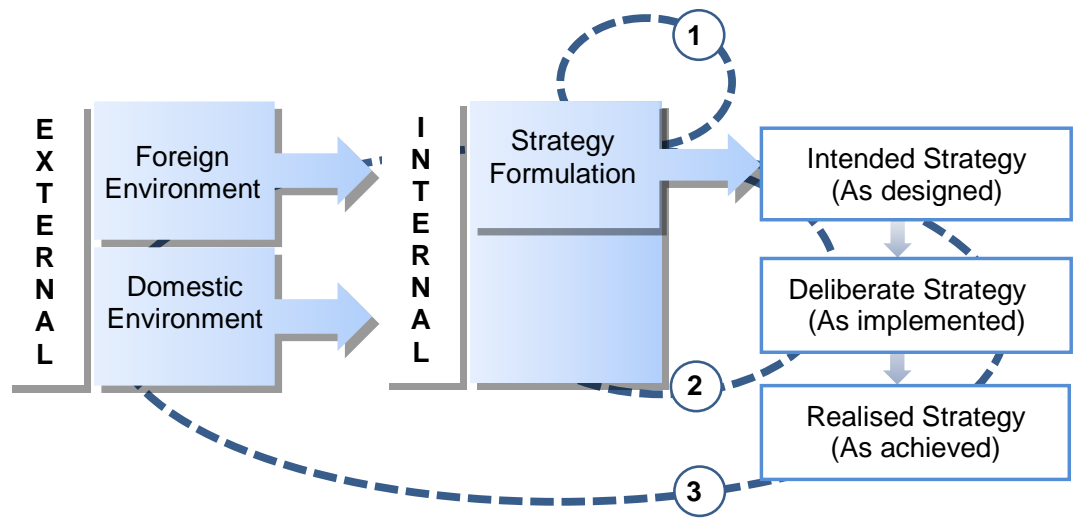

Figure 5: Forming realised strategy

Compared to the second feedback loop (which dealt with the discrepancy between the actual outcomes of the strategy and its declared objectives), the third loop presupposes a continuous comparison between realised strategy and the realities of the external environment instead. By weighing up the developed capabilities of the organisation (or the lack of it) against the current demands of the operational environment, this mechanism relentlessly questions the validity of both the intended and deliberate strategies. Expressed in terms of the VSM, the third loop is part of the adaptation mechanism of the organisation: a sensing/intelligence device, premised upon the enhancement of effectiveness and creativity. It is also future-oriented, linking the changing external environment with the primary activity 
of the organisation (its core business or raison d'être) through the production of revised policy. ${ }^{60}$ In contrast with the second feedback loop, which aids organisational efficiency in 'doing things right', this one biases the institution towards operational effectiveness in finding 'the right things to do'. By adding the third loop, the schematic now resembles the type of double-loop organisational learning that Argyris and Schön (1978) describe, and approaches a strategic management model with which the dynamic school would be more comfortable. ${ }^{61}$ However, it is precisely in this realm of strategy formation that the constructs of the design school begin to take serious strain. Strategists from the design school are inherently averse to the intuitive, holistic, mutable approach that the external adaptation loop implies. They tend to slight the influence of emergence, and are therefore less responsive to strategic context; furthermore, they are inclined to separate the formulation of strategy from its implementation (and strategic thinkers from strategy's doers), both in hierarchical primacy and antecedent in time. ${ }^{62}$

This does not imply that the dynamic school model would be strategists' first choice under all circumstances, though - there are times of stability when the design school approach might actually work better. However, under most operating conditions, the majority of organisations have to contend with a flood of influences from their external environment, to the extent that all of their realised strategies contain elements from both emergent and deliberate strategy formation. ${ }^{63}$ The effects of emergence would be even greater during or immediately after major shifts in context, such as that which the SANDF would have been operating under during the first decade of its founding. Under such conditions of uncertainty, responsive organisations will attempt to become more effective by deliberately connecting thought and action so intimately that the information feedback loops condense into a continuous spiral of strategy formulation-implementation-formulation cycles (the familiar OODA loops again). ${ }^{64}$ A responsive organisation would then be intent upon simply coping as best it could, learning as rapidly as possible, and continuously probing its way towards a new strategic paradigm - organisational behaviour that strategists from the design school often connote negatively with adverse effects such as 'strategic erosion', 'improvisation', 'opportunism' or 'strategic drift'. ${ }^{65}$ Moreover, the belief that strategy formulation is a controlled, conscious thought process, conducted over time, and giving birth to fully explicated strategies that the organisation implements thereafter, exacerbates the consequences of the design school strategist's cognitive bias. ${ }^{66}$ Modern militaries have become aware that strategic thinkers and planners are incapable of calculating everything in advance, and that intended strategies will always be incomplete and sometimes even blatantly wrong. On the other hand, more conservative defence forces may find that, during the unavoidable delay between the implementation of intended strategy and the 
realisation of strategic outcomes, they have analysed and planned themselves into obsolescence. This risk of increasing entropy would be all the more plausible for a military that does not receive regular feedback from active participation in combat operations, such as an SANDF in peacetime.

\section{Feedback loops as facilitators of ambiguity}

The lags that are characteristic of feedback loops create problems for a strategist who seeks predictability and control of the outcomes of the strategy. Some management activities are subject to inertia or delay (occasionally measured in years), which temporarily conceals the ultimate consequences of strategic behaviour. Inertia implies that elements within the organisation tend to maintain their initial state over time, and only change eventually in accordance with the net imbalance between the different forces acting upon those constituents. To an organisation bent on deliberate transformation, inertia may be judged 'better' or 'worse', depending on the nature of its contribution towards the achievement of the strategic objectives of the institution. An example of the former would be an SANDF maintaining its administrative competency due to the retention of well-trained staff from a previous dispensation, while an illustration of the latter would refer to an SANDF that has to cope with legacies of racism and sexism from the same era. The concept of delay, on the other hand, refers to a change of output that relates directly to the adjustment of input, but separated by a finite interval of time. For a strategist of the design mould, delay is generally not 'good'; it contributes to uncertainty, risk and complex dynamic behaviour, and it is demanding of organisational flexibility to resolve the potential loss of control. The probability of unintended consequences becomes even more significant for an organisation in the throes of transformation (such as the SANDF of a decade ago) when one considers that any process involving organisational learning and culture change is equally subject to the intrinsic delays of feedback loops. ${ }^{67}$ To cap it all, some of the delayed outputs of the feedback loops actually reinforce the original inputs of the strategy. The promotion of personnel for reasons other than professional competency, for example, could generate multiplier effects that not only amplify organisational disorder, but may also produce exponential growth in similar appointments. ${ }^{68}$

There are more hazards for an organisation such as the SANDF, which had been transforming from one state of stable equilibrium to another. Under these conditions, managers are often under the impression that the system invariably migrates to new behavioural patterns that are orderly, regular and consensual, partly because of their own actions, and partly because of the natural tendency of the system towards social convergence. Management then believes that the interim states of the organisation are transient, of lesser consequence, and undemanding of 
major intervention. In practice, though, the deliberate transition from an existing condition of stability to the desired end-state of a transformation strategy may prove to be unnavigable, with the result that systemic failure transpires before the organisation attains the desired equilibrium. ${ }^{69}$ It is therefore a combination of feedback loops, with their implied inertia and delays, which allows one to connect the management paradigm of the SANDF with its strategic behaviour. This concept also permits the generation of useful theories that explain those aspects of the organisation's strategy formation that may otherwise be incomprehensible. (For example, Figure 5 shows three feedbacks loops that conjoin at the strategy formulation centre of an organisation, where personnel representing the intelligence and operational control functions should be in constant communication and interaction with each other. Here, too, senior management should be monitoring the on-going strategic debates, with the express purpose of learning about those key issues that should drive the strategy of their organisation. ${ }^{70}$ Could an absence of these frank discussions in the SANDF not have contributed to the formation of inappropriate strategy?) One can now expand the line of argumentation by asking where the major concerns for an internal debate might have arisen from, and how armed forces generally determine the importance and urgency of those issues for the making of force development strategy.

\section{Unpacking the context of strategy formation}

In the normal order of things, defence policy follows on a national security strategy, which one can describe as "the process of maintaining, coordinating and employing the assets of the security sector so that they contribute optimally to the nation's strategic goals". ${ }^{71}$ A defence policy should therefore only be one of many governmental policies, all premised on the imperatives of an explicit national security strategy. This is not the case in South Africa, though, since government has failed to publish such a document since democratisation in 1994 - a fact implicitly recognised by the draft Defence Review 2012, when it speaks of the "emergent national security strategy". ${ }^{72}$ Nevertheless, such an omission is by no means fatal to policy making, if one agrees with Huntington's view that defence policy is neither the outcome of a clear pronouncement of national objectives nor entirely the result of military logic. ${ }^{73}$ In contrast to the planning of other state departments (agriculture, economic affairs or education, for example), defence preparations are subject to a much greater degree of uncertainty and unquantifiable risk, which implies that the making of defence policy is never a wholly rational process in any case. ${ }^{74}$ One can therefore consider defence policy as a political statement of the inevitable interplay between foreign policy (where the allocation of values affects relations between national states) and domestic policy (where the actions of government affect the 
allocation of values among groups within society). ${ }^{75}$ In Figures 3 to 5 , the study has grouped these two dimensions together under the external environment.

Dandeker, in an article on civil-military relations, adopts a similar tack. He describes the first-mentioned domain as the international context of civil-military relations, from which those risks, threats and opportunities arise that prompt governments to create military organisations in the first place. ${ }^{76}$ This setting connotes with the 'functional imperative' of strategy, where states are concerned with the demands of international politics, the goals of foreign policy, and the development of military strategy. Cognition of the functional imperative should result in policy expressions of instrumental or utilitarian decisions that concern the deployment, commitment and employment of armed forces. The second domain, on the other hand, refers to a country's domestic context, comprising of social, economic, technological, political, and - significantly for the purposes of this article - cultural factors. As we have seen during the discussion on the evaluation of strategy options, defence policy and military strategy are obliged to accommodate the cultural values of the host society, even if these appear to be in conflict with tenets of the accepted military ethos (such as formal discipline, subordination of the individual to the group, and unquestioning obedience to superiors). ${ }^{77}$ Concern with the 'societal imperative' in defence also gives rise to structural (as opposed to military-strategic) policy decisions:

- The size and distribution of the armed forces' budget;

- $\quad$ The composition, numbers and service conditions of defence personnel;

- The procurement and distribution of equipment and commodities to the defence force; and

- The models and processes by which the military is organised and administered. $^{78}$

Defence policy - and force development strategy - consequently has to reconcile concurrent demands from both the foreign and domestic policy environments, in ways that balance international security risks with the internal security demands of stakeholder groups within society. ${ }^{79}$ While Dandeker therefore advocates the necessity for policy makers to maintain an appropriate balance between the functional and societal imperatives, he continues to add a third, internal dimension to the context of strategy formation. He calls this "the weight of history", which is comprised of (among others) the particular society's experience of war, the social status and positional power of their military, and society's history with conscription - all of which are associated with a defence force's sources of strategic culture, as discussed later in the article. ${ }^{80}$ A connection between this organisational imperative and the societal and functional imperatives is also established when 
Dandeker says, “... in adjusting to changes in society and international security, [leaders] have to take into account the history and traditions of the individual armed services, which are normally critical factors in sustaining their identity, sense of shared purpose and morale". ${ }^{81}$ To this, one may add the history, traditions and structures of the formations within the services, and conclude that decision-makers are obliged to formulate defence policy and military strategy in acknowledgement of a triptych of imperatives, and not merely of the pair postulated by Huntington.

In summary, the study therefore presents the strategic imperatives as firstly the functional, being a distillate of the strategic context and focused on rendering effective militaries; and secondly, the societal, being a reaction to the perceived needs of a citizenry that (in democracies, at any rate) provides resources and on whose behalf the military conducts its business. Whereas strategists of the design school are inclined to describe the functional and societal imperatives as one concept (the external environment), the analysis has now confirmed that it actually consists of two discrete domains. ${ }^{82}$ Through Dandeker's description of the internal context, it was further possible to draw the management activities related to strategy initiation, analysis, evaluation, selection and monitoring into a single organisational imperative. $^{83}$ Apart from the aforementioned 'rational' strategy-formation behaviours, though, the internal context also accounts for the beliefs, values, norms and collective mind-sets of the organisation - its organisational culture(s), in other words. In the section on the evaluation of strategy options, the study has already indicated that the cultural beliefs of strategists could influence their perceptions of reality more than impartial analyses do. Moreover, it is possible that an organisational culture could reinforce some aspects of its members' original mental maps and eventually turn these maps into paradigms - archetypes that become unquestioned truths and subsequently obstruct organisational learning. ${ }^{84}$ As previously intimated during a brief discussion of John Boyd's OODA loop, these paradigms could not only have significant implications for initial strategy formulation, but they could also bias strategists' perception and understanding of the external and internal environments during continued strategy formation.

By themselves, tacit cultural biases are not necessarily at odds with the forming of appropriate strategy. When in the company of strong political forces, however - as when strategy requires organisational restructuring at senior level, or when it threatens to undermine existing power bases - cultural bias may debilitate an organisation. ${ }^{85}$ In such cases (as presumably with the SANDF in the first decade after its establishment), strategists would do better by recognising and challenging not only their own set of assumptions and beliefs, but also those held collectively by the organisation for which they are strategizing. Crucial to this balancing process 
would be the development of analytical processes that provide objective data for scrutiny, accompanied in parallel by a continuous dialogue that does not collude or reinforce the institutional paradigm, but instead questions and confronts it. ${ }^{86}$ An organisation in a prescriptive strategy formulation mode, though, would be inclined to favour rational analysis over this type of internal debate - in effect, it would identify with strategy formation as a process of intellectual conception, rather than as the consequence of organisational learning. ${ }^{87}$

\section{Conclusion}

By this time, the study has presented sufficient evidence to show that adherence to the management model of a design school, as opposed to that of the dynamic school, may at least be partially responsible for the strategic failure of a defence force. The argument started with the assumption that the military effectiveness of the SANDF has been suspect for a while now, due to the dynamic interaction between two causal variables: the preferred strategic management model of the organisation, and defence's acquired strategic culture. Regarding the first element, militaries generally tend to espouse the design school approach to strategy formation, where the top echelons of the organisation generate an intended strategy, then delineate and express it overtly, and thereafter oversee its implementation. During this process, influences from three contextual domains constrain the behaviour of strategists. Two of these are external to the relevant institution (the functional and societal imperatives), while the third comprises of checks and balances from inside (the organisational imperative). Whereas consideration of the functional imperative will shift the focus of a defence force towards military effectiveness, emphasis of the societal imperative will encourage a concern with the particular military's structure, service conditions and cost-efficiency. The organisational imperative, on the other hand, ensures the expression of institutional culture in strategy formulation and moderates the influences of the external environment on strategy formation. It serves as a sensory filter for the strategist's observations, guides understanding of the situation, influences the evaluation of strategy options, and focuses strategic behaviour. Regardless of the institution's choice of strategic management model, the subconscious beliefs of decision-makers will therefore have a crucial influence on strategy formation.

The organisational imperative is located at the centre of a web of feedback loops, of which the current study has concerned itself with only three. First among these is an assessment loop within the strategy formulation body that pronounces on the appropriateness of intended strategy; secondly, there is an internal control loop that (in the design school model) should align the outcomes of a strategy with its declared intent. Both of these loops exist within a closed strategic management 
system and offer no solutions to the problem of increasing organisational entropy. This leaves the third, external feedback loop, which should be utilised to enable responsiveness to the organisation's operating environment. In combination, the proper employment of these feedback loops enhances organisational learning and ensures that the realised strategy conserves the functional effectiveness of the organisation. However, because strategists of the design school are prone to undervalue the influence of the external environment on strategy formation, they have insufficient inclination to manipulate emergent strategy. Their organisations may therefore be prone to particular afflictions (such as institutional scotomas, ideological fixation, and organisational entropy) at any time, but even more so if they apply their management model at an unsuitable stage of the establishment's evolution. Due to the delays and inertia that are inherent to feedback loops, the strategic risk increases further in organisations that are unresponsive to their environments. While delays may allow a peacetime defence force to postpone the consequences of an inappropriate strategy for a while, any undesirable outcomes will be that much harder to turn around when they eventually do become manifest especially when one considers that some loops feed upon themselves, create multiplier effects, and have the potential to destabilise the organisation as a whole. Despite everything suggested thus far, though, the extent to which an organisation such as the SANDF will suffer the deleterious consequences of an inappropriate management model would still be largely dependent upon its cultural reflexes. Part 2 of the study will explore this supposition further.

\section{Endnotes}

${ }^{1}$ Brodie, B. War and politics. New York: Macmillan, 1973, 332.

2 "Speech by Nosiviwe Mapisa-Nqakula, Minister of Defence and Military Veterans on the occasion of the Department of Defence Budget Vote 2013”. South Africa Government Online. <http://www.info.gov.za/speech/DynamicAction? pageid $=461 \&$ sid $=36705 \&$ tid $=107903>$

3 "Speech by LN Sisulu, Minister of Defence and Military Veterans on the occasion of the Department of Defence Budget Vote 2012". Politicsweb. <http://www.politicsweb.co.za/politicsweb/view/politicsweb/en/page71654? oid=299448\&sn=Detail\&pid=71616>

${ }^{4}$ Römer Heitman, H. The battle in Bangui: The untold inside story. Johannesburg: Parktown Publishers, 2013, 36-38.

5 "Speech by Nosiviwe Mapisa-Nqakula" op cit. The minister was referring to the SANDF's mission to Bangui, a spate of military aviation accidents, and the unauthorised use of the Waterkloof air force base.

${ }^{6}$ Republic of South Africa. "White Paper on Defence, May 1996". <http://merln.ndu.edu/whitepapers/SouthAfrica1996.pdf> 
${ }^{7}$ Republic of South Africa. "South African Defence Review 1998". 〈http://merln.ndu.edu/whitepapers/SouthAfrica1998.pdf>

8 "Briefing by Minister of Defence \& Military Veterans on Department Budget 2009/10”. Parliamentary Monitoring Group.

<http://www.pmg.org.za/print/briefing/20090703-briefing-minister-defencemilitary-veterans-department-budget-20091>

${ }^{9}$ Republic of South Africa. "South African Defence Review 2012 (Consultative Draft)". Department of Defence. <http://www.info.gov.za/view/DownloadFileAction?id=163570>

${ }^{10}$ Jane's Defence Weekly 47/50. 15 December 2010. 44.

${ }^{11}$ From the American Heritage Dictionary of the English Language $\left(4^{\text {th }} \mathrm{ed}\right)$ and the Collins English Dictionary (available at http://www.thefreedictionary.com/entropy). Simply stated, entropy is a measure of the amount of energy that is not available to do work in the thermodynamic process: as entropy increases (the natural state of affairs, in a closed system), the available energy is dissipated, and disorder, randomness and stasis escalate.

${ }^{12}$ Mintzberg, H. “Patterns in strategy formation”. Management Science 24/9. 1978. 945-946.

${ }^{13}$ See speech by David Maynier, 6 July 2009. <www.politicsweb.co.za/politicsweb/view/politicsweb/en/page71619?oid>

${ }^{14}$ See article by Gibson, E. "Knyp en kannibaliseer”. Beeld. 2 August 2013.

${ }^{15}$ Kasrils, R. "Progress in transformation". In Cilliers, J (ed), Continuity in change: The SA Army in transition. ISS Monograph Series 26. August 1998. 16-17. Ronnie Kasrils was the Deputy Minister of Defence in 1998 and, along with the Minister of Defence, also a former member of MK.

${ }^{16}$ Louw, GM. " South African Defence Policy and capability: The case of the South African National Defence Force". MMil thesis. University of Stellenbosch, 2013.

${ }^{17}$ Gray, CS. Modern strategy. New York: Oxford University Press, 1999, 129.;

Atkeson, EB. "The dimensions of military strategy". Parameters VII/1. 1977. 4152.

${ }^{18}$ Papageorgiou, G \& Hadjis, A. " Strategic management via system dynamics simulation models". World Academy of Science, Engineering and Technology 59. 2011. 229. <www.waset.org/journals/waset/v59/v59-45.pdf>

${ }^{19}$ Bartholomees, JB. “ A survey of the theory of strategy”. In Bartholomees, JB (ed), The US Army War College guide to national security issues $\left(4^{\text {th }} \mathrm{ed}\right.$, Vol. 1$)$, Carlisle: US Army War College Strategic Studies Institute, 2010, 15.

${ }^{20}$ Mintzberg op. cit., p. 935.

${ }^{21}$ South Africa had yet to publish a declared security strategy at the time of this paper's writing. A prospective researcher would therefore be largely reliant upon inferences from departmental policies to demarcate a security strategy - strategy as pattern, rather than strategy as planning.

${ }^{22}$ Mintzberg op. cit., p. 935.

${ }^{23}$ Ibid., p. 945. 
${ }^{24}$ Gray op. cit., p. 50.

${ }^{25}$ Ibid., p. 228.

${ }^{26}$ Papageorgiou \& Hadjis op. cit., p. 228.

${ }^{27}$ Mintzberg, H. “ The design school: Reconsidering the basic premises of strategic management”. Engineering Management Review 19/3. Fall 1991. 94-99.

${ }^{28}$ Ibid., p. 98.

${ }^{29}$ Yarger, HR. " Toward a theory of strategy: Art Lykke and the US Army War College Strategy Model". In Bartholomees op. cit., p. 50.

${ }^{30}$ Brooks, RA \& Stanley, EA (eds). Creating military power: The sources of military effectiveness, Stanford, CA: Stanford University Press, 2007, 2-12.

${ }^{31}$ Fowler, A. "Systems modelling, simulation, and the dynamics of strategy". Journal of Business Research 56. 2003. 139.

${ }^{32}$ Moncrieff, J. "Is strategy making a difference?" Long Range Planning 32/2. 1999. 273.

${ }^{33}$ Fowler op. cit., p. 136.

${ }^{34}$ Authors such as Henry Mintzberg would contest this simple binary typology, identifying up to 10 distinct schools of thought (Mintzberg op. cit., p. 85).

${ }^{35}$ Fowler op. cit., p. 136.

${ }^{36}$ Yarger op. cit., pp. 46-48.

${ }^{37}$ Ibid., p. 48.

${ }^{38}$ Yarger, HR. " The strategic appraisal: The key to effective strategy". In Bartholomees op. cit., p. 53.

${ }^{39}$ Ibid., p. 51.

${ }^{40}$ Mintzberg op. cit., p. 87.

${ }^{41}$ Ibid., p. 91. This observation seems to establish a correlation between prescriptive strategy-making on the one hand, and the 'mission command' philosophy in military operations on the other. Mission command is a style of military license that advocates a relatively decentralised subsidiary of command, promoting initiative and speed of action, within predefined constraints.

Orders provide only enough detail to establish the commander's intent and objectives, allowing freedom of action during execution thereafter. The civilian management concept of 'workplace empowerment' relates closely to mission command in the military.

${ }^{42}$ Yarger, "Toward a theory of strategy ..." op. cit., p. 45.

${ }^{43}$ Ibid., p. 50.

${ }^{44}$ Bartholomees op. cit., p. 16.

${ }^{45}$ Downey, FM \& Metz, S. “ The American political culture and strategic planning”. Parameters, September 1988. 34.

${ }^{46}$ Ibid.

47 Ibid.

${ }^{48}$ Bartholomees op. cit., p. 16.

${ }^{49}$ Ibid., p. 17.

${ }^{50}$ Ibid.

${ }^{51}$ Holcomb, JF. “ Managing strategic risk”. In Bartholomees op. cit., p. 70. 
${ }^{52}$ The OODA Loop concept does not require any introduction - a simple Google search will immediately render more than 134000 results.

${ }^{53}$ Mintzberg op. cit., p. 137; Papageorgiou \& Hadjis op. cit., p. 230.

${ }^{54}$ Fowler op. cit., p. 136.

${ }^{55}$ Espejo, R. " The Viable Systems Model: A briefing about organisational structure". 2003.

$<$ http://library.uniteddiversity.coop/Systems_and_Networks/Viable_Systems Model/INTRODUCTION\%20TO\%20THE\%20VIABLE\%20SYSTEM\%2 OMODEL3.pdf>

${ }^{56}$ Mintzberg op. cit., p. 93.

${ }^{57}$ Ibid.

${ }^{58}$ Ibid.

${ }^{59}$ Fowler op. cit., p. 137.

${ }^{60}$ Espejo op. cit., pp. 26-32.

${ }^{61}$ Fowler $o p$. cit., p. 136. In single-loop learning, an organisation would modify its actions according to the perceived difference between expected and obtained outcomes. Within the double-loop learning paradigm, the organisation will interrogate the values, assumptions and policies that led to those actions in the first place - a higher order of learning about single-loop learning, in other words.

${ }^{62}$ Mintzberg op. cit., pp. 91-94.

${ }^{63}$ Ibid., p. 95.

${ }^{64}$ For the strategist, 'observe' means sensing (environmental scanning); 'orient' implies sense-making (analysis and uncovering of meaning); 'decide' signifies determining a course of action; 'act' denotes implementation.

${ }^{65}$ Mintzberg op. cit., p. 88.

${ }^{66}$ Ibid., pp. 88-90.

${ }^{67}$ Fowler op. cit., p. 137.

${ }^{68} \mathrm{Ibid}$; Papageorgiou \& Hadjis op. cit., p. 230.

${ }^{69}$ Ibid.

${ }^{70}$ Espejo op. cit., pp. 31-32.

${ }^{71}$ Chuter, D. Governing and managing the defence sector. Pretoria: Institute for Security Studies, 2011, 13.

${ }^{72}$ Republic of South Africa, "South African Defence Review 2012" op. cit., p. 44.

${ }^{73}$ Huntington, SP. " The two worlds of military policy". Horton, FB III, Rogerson, AC and Warner EL III, (eds), Comparative defence policy, Baltimore, MD: John Hopkins University Press, 1974, 108.

${ }^{74}$ Chuter op. cit., p. 137.

${ }^{75}$ Huntington op. cit., p. 108.

${ }^{76}$ Dandeker, C. " Military and society: The problem, challenges and possible answers". King's College, London. 2003. $\langle$ https://kclpure.kcl.ac.uk/portal/en/publications $>$ Dandeker makes a useful distinction between risks (capacities that have the potential to cause harm to the state's security) and threats (arising when such capacities become associated with intent to cause harm). 
${ }^{77}$ Ibid.

${ }^{78}$ Huntington op. cit., p. 109.

${ }^{79}$ Ibid., p. 108.

${ }^{80}$ Lantis, JS \& Howlett, D. “ Strategic culture”. In Baylis, J, Wirtz JJ \& Gray, CS (eds), Strategy in the contemporary world $\left(3^{\text {rd }} \mathrm{ed}\right)$, New York: Oxford University Press, 2010, 89-92.

${ }^{81}$ Dandeker op. cit., p. 3.

${ }^{82}$ Mintzberg op. cit., p. 87.

${ }^{83}$ Ibid., p. 92.

${ }^{84}$ Moncrieff op. cit., p. 274.

${ }^{85}$ Ibid., p. 275.

${ }^{86} \mathrm{Ibid}$.

${ }^{87}$ Mintzberg op. cit., p. 92. 